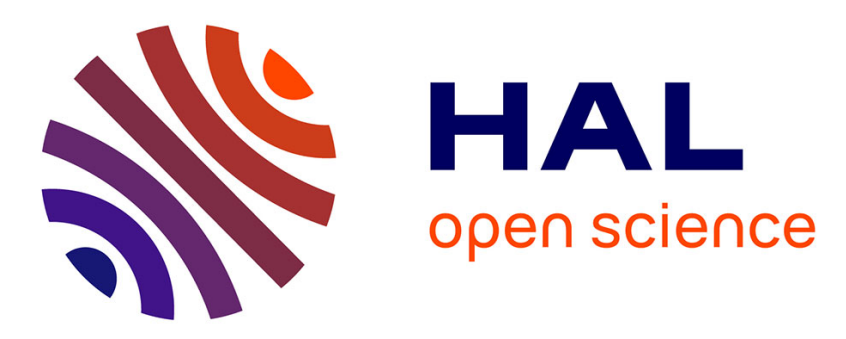

\title{
On the Categorical Nature of the Process Involved in Schwa Elision in French
}

\author{
Audrey Bürki, Cécile Fougeron, Cédric Gendrot
}

\section{To cite this version:}

Audrey Bürki, Cécile Fougeron, Cédric Gendrot. On the Categorical Nature of the Process Involved in Schwa Elision in French. Interspeech, Aug 2007, Antwerp, Belgium. pp.1026-1029. halshs-00189740

\section{HAL Id: halshs-00189740 \\ https://shs.hal.science/halshs-00189740}

Submitted on 6 Jan 2017

HAL is a multi-disciplinary open access archive for the deposit and dissemination of scientific research documents, whether they are published or not. The documents may come from teaching and research institutions in France or abroad, or from public or private research centers.
L'archive ouverte pluridisciplinaire HAL, est destinée au dépôt et à la diffusion de documents scientifiques de niveau recherche, publiés ou non, émanant des établissements d'enseignement et de recherche français ou étrangers, des laboratoires publics ou privés. 


\title{
On the Categorical Nature of the Process Involved in Schwa Elision in French
}

\author{
Audrey Bürki ${ }^{12}$, Cécile Fougeron ${ }^{1}$, Cédric Gendrot ${ }^{1}$
1Laboratoire de Phonétique et Phonologie, UMR7018, CNRS-Paris3/Sorbonne Nouvelle, France ${ }^{2}$ Laboratoire de Psycholinguistique Expérimentale, Université de Genève, Suisse \\ audrey.buerki@pse.unige.ch; \{cecile.fougeron; cedric.gendrot\}@univ-paris3.fr
}

\begin{abstract}
This paper examines the nature of the process involved in optional schwa elision in French. More specifically, it aims at testing whether this process is gradual or categorical, on the basis of an analysis of the distribution of the duration of over 4000 schwas extracted from a large corpus of continuous speech. The distribution observed is bimodal, with absent schwas (at 0 ms duration) on one side, and realized schwas on the other side, the two groups being separated by a small gap in the distribution. Realized schwas present cases of strong temporal reduction, but this reduction does not show a continuous pattern toward zero duration, as would be predicted if schwa elision was the end-point of a gradual reduction process. Different interpretations of this distribution are discussed.
\end{abstract}

Index terms: schwa elision, french, categorical process

\section{Introduction}

Schwa elision in French is defined as the alternation between two variants of a same lexical entry containing or not a schwa. For example, the word 'fenêtre' (window) can be equally pronounced as a schwa-full form [fənets] or as a schwa-less form [fnets]. Various factors are known to affect the realization of one or the other variant (speech style, speaker age and dialect, position in word, etc...), although the choice for one or the other variant is not fully predictable.

The alternation between schwa-less and schwa-full forms has been interpreted as either a vowel deletion process, or a vowel epenthesis process (see [1] for other accounts). Be it a deletion or an epenthesis, traditional phonological accounts assume that the process is complete, and results from a rulebased segmental process.

As part of a larger project on the nature of schwa and schwa elision in French, the present study aims at determining whether experimental evidence can be found to assess the categorical nature of this process. Only few acoustic or articulatory studies have addressed this question. They have usually focused on the phonetic properties of the consonant sequences resulting from the elision of schwa, asking whether some residues attributable to schwa remain in cases where the vowel is apparently absent. Consonant sequences resulting from schwa elision are thus compared to similar consonant sequences not resulting from elision. Results usually agree on the fact that the former differ from the latter. However, while these acoustic or articulatory differences are always taken to reflect remnants of the vowel, their existence is not always interpreted in the same way.

In [2] for example, the observed acoustic differences between sequences of the type 'le bar trouvé' vs 'le bas r'trouvé' (the apostrophe indicating the elision, the bar found vs the sock found again) are attributed to the fact that in the second case the sequence retains its phonological nucleus despite the loss of its segmental content. A palatographic study, [3] found articulatory differences when comparing consonant sequences resulting from schwa elision (e.g. 'pas d'rôle', no role) to underlying onset clusters (e.g. 'pas drôle', not funny) and consonant sequences spanning a word boundary (e.g. 'jade rose', rose jade). They do not take these results as evidence for the maintenance of the syllable, but rather interpret them as a preservation of the pre-vocalic underlying articulatory specification of the consonants, despite the deletion of schwa. In her formalization of these results, [4] considers that these characteristics of the surrounding consonants, inherited from the form with schwa, are extended to the form where the schwa is categorically elided following Paradigm Uniformity principles.

While these interpretations ([2, 3, 4]) have different implications, none of them raises doubts about the fact that the absence of schwa results from a categorical segmental process. This is not the case of other studies, which consider the phonetic differences observed in [2] and [3] as evidence for a gradual reduction process. According to the analysis proposed for English schwa elision within the Articulatory Phonology framework [5], schwa elision in French would be the consequence of a gradual process of overlap between gestures. According to this view, in apparent schwa-less French forms, the vowel is not acoustically or perceptualy visible, not because of segmental deletion, but because it is hidden by the overlap of the surrounding consonantal gestures. So-called schwa elision would thus be the end point of this gradual reduction mechanism. In that sense, it is similar to the other coarticulatory or allophonic variations, explained by the overlap of invariant underlying gestures. Support for this overlap account in French is found in the results of [6] who observed some lingual gestures attributable to schwa in apparent schwa-less forms, and in the results of [7] who observed some remnants of the rounded articulation of the elided schwa on the surrounding consonants.

Although these results have received contradictory explanations or have failed to be replicated (see [1]), their major shortcoming resides in their assumption that schwa elision in French is a 'casual speech' or 'fast speech' process. Their argument is that in casual or fast speech, overlap is known to increase, and thus schwa has more chance to be fully overlapped (thus hidden). However, even though it is well agreed upon that there are more schwa elisions in casual and fast speech style in French, schwa-less variants do occur frequently at slow and formal speech styles. It cannot thus be reduced to a continuous speech process.

In a recent paper, [8] examined the acoustic properties of consonant sequences resulting from the elision of schwa in English. Her results confirm the existence of acoustic residues attributable to schwa in apparent schwa-less forms. Following [5], she also argued that these residues are better accounted for by a change in gestural overlap, rather than segmental deletion. More interestingly, although she manipulated speech rate to trigger schwa elision, she observed that some of her speakers also produced elision at normal rates. This leads her to interpret elision at fast and at normal rate by the same process of overlap, a categorical shift toward a more 
overlapping coordination pattern between gestures. Hence, vowel elision, although explained by overlap, would not only result from a gradual reduction process, but could be the consequence of a categorical change in the specification of the coordination of the gestures. According to Articulatory Phonology principles, this specification is assumed to be assigned by the phonological system. While this hypothesis has to be further elaborated to be applied to schwa alternation in French, it reconciles the views that elision may be due to overlap and that this process would be categorical.

This review of the literature shows that determining whether schwa elision is a gradual or categorical process in French is not straightforward. In this study, our goal is to question the nature of the schwa-zero alternating process, but our focus is not on the potential acoustic or articulatory residues of schwa in apparent schwa-less forms. Our approach is different. Rather than focussing on cases where schwa is acoustically and perceptively absent, as done in the studies presented above, we concentrate our attention on the different realizations of words containing a schwa (in their schwa-less and schwa-full forms). This is done by observing the production in continuous speech of a large variety of words uttered by a large number of different speakers. Our hypothesis is that variations in the realization of these words can inform us about the nature of the process. More specifically, we test whether the realizations of this vowel follow a continuous pattern of reduction ranging from a full vowel realization to a fully absent vowel (i.e. the end point of a reduction continuum), or whether two categories emerge: cases with full vowels on one side, and with completely deleted vowels on the other side. Support for a categorical process would be found in a bimodal distribution with a gap in the distribution between the 2 groups. Support for a gradual process would appear in a continuous distribution (without a gap).

\section{Method}

A repertory of 18553 French words containing a schwa (obligatory or optional, not occurring at word or clitic boundaries or in compounds) was created through the compilation of several lexical databases (Lexique [9], Brulex [10], IlPho [11], Grand Robert dictionary). In order to observe the realization of a large number of lexical forms produced by many speakers, we selected the ESTER corpus containing $24 \mathrm{~h}$ of radio broadcasted news including productions of a total of 574 speakers [12]. We decided to discard schwas appearing before derivational suffixes or inflectional endings.

Our focus was on schwas that can alternate with $\varnothing$. Two types of schwa are described in French: optional (alternating) schwas and obligatory schwas (always produced). While some words contain unambiguous obligatory schwas (e.g. 'belette', weasel), for other it is in practice very difficult to assert if the schwa is optional or not. A first intuitive categorization of a subset of the corpus according to whether the word could be 'heard' without its schwa, revealed a great disparity in the judgements of the 3 authors. Thus, in order to select our test items, we decided to choose a more objective method based on the analysis of the actual realization of these words in our speech database. On the basis of the transcription given by the automatic recognition system developed at IRISA, we selected the words that were recognized by the system as being produced in the corpus sometimes in their schwa-less form, sometimes in their schwa-full form. After elimination of the production of 22 speakers having a strong foreign accent, and of 95 occurrences showing a clear recognition error or having a bad acoustic quality, 4320 occurrences (corresponding to 203 different words) were selected for analysis.

A manual examination of the output of automatic recognition system was undertaken for all the sound files in order to correct schwa detection errors (wrong omission / insertion). Since the shortest segment duration assigned by the system is $30 \mathrm{~ms}$, and since the automatic alignments are far from being reliable with respect to the precision required in this study, duration measurements could not depend on this automatic segmentation. Automatic segmentations / alignments were thus corrected manually, according to the following criteria. We considered a schwa as being realized if it presented a voiced portion and a formant structure. Fully devoiced vowels were thus not considered as schwas. The onset and offset of the vowels were determined based on the signal periodicity and on apparition / disappearance of the second formant, as illustrated in the segmentation shown in Figure 3. These criteria for segmentation of the vowel intervals were the best compromise with regard to the wide variety of consonantal contexts. As can be seen in the example of 'semaine' in Figure 3, the duration of the segment corresponding to our definition is much shorter than if we had included voiceless portions of the vowel. The consequences of this type of segmentation are discussed in section 4 . The duration of the schwa intervals was then automatically computed with Praat [13].

In order to avoid potential confounds due to factors known to affect the frequency of schwa elision, the words present in the corpus were coded according to both their syllabic position in the word, and their location relative to a morpheme boundary. Schwas in word-initial syllables are known to be less frequently elided than non-initial schwa, while morpheme-internal schwas are more consensually considered as underlying lexical schwas compared to those located at morpheme boundaries [see[[14]].

\section{Results}

\subsection{General distribution of duration}

The distribution of the duration of the 4185 optional schwas of our corpus is illustrated in Figure 1. This distribution is divided into two sub-groups. It excludes $4 \%$ of the occurrences, whose duration was over 2 standard-deviations away from the mean.

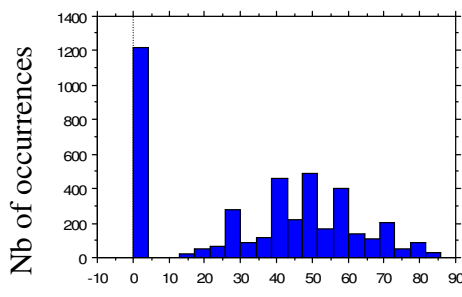

Schwa duration

Figure 1 : Distribution of the schwa durations

On one side, at $0 \mathrm{~ms}, 1215$ occurrences $(29 \%)$ of the words containing an optional schwa were produced with a complete absence of voicing and formant structure. According to our criteria, these forms are considered as schwa-less. As an illustration of these cases, a schwa-less occurrence of the word 'sera' (will be) is presented in figure 2. On the other side, between 16 and $86 \mathrm{~ms}, 71 \%$ of the occurrences present a vocalic portion corresponding to a schwa. Confirming the 
literature, these 2970 realized schwas in our corpus are relatively short vowels, with a mean duration of $49 \mathrm{~ms}(\sigma=$ $15)$. The distribution of the duration of these schwa-full forms is unimodal with close to zero skewness (0.13) and kurtosis (0.52 ) coefficients. Figure 3 shows two examples of schwa-full occurrences of the words 'sera' (will be) and 'semaine' (week).

More interestingly, with regard to our acoustic criteria, no schwas were observed with a duration of less than $16 \mathrm{~ms}$, thus a gap is observed in the distribution beween 0 and $16 \mathrm{~ms}$. This gap in the duration distribution between the 2 subgroups is in favour of a categorical process. It has to be noted that the outliers we removed on the left-hand side of the distribution represent only $0.7 \%$ of the schwa-full forms distribution. This removal cannot therefore be responsible for the gap we observe.

It also has to be mentionned that the distribution is similar when the words having a schwa in an /R/ context (words difficult to segment) are excluded previously from the analysis.
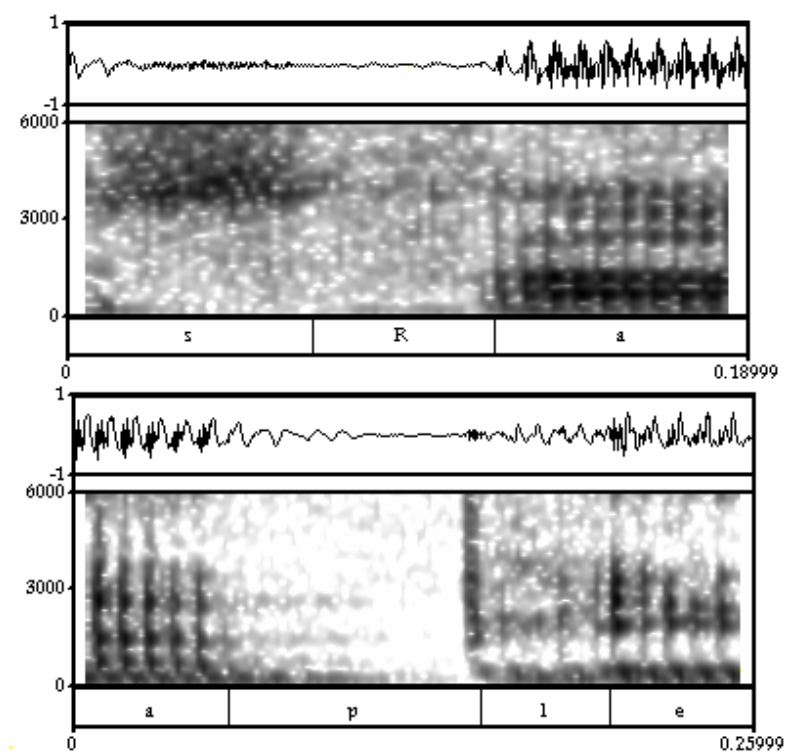

Figure 2: Schwa-less occurrences of the word 'sera', will be (note that the $/ R /$ is devoiced) and 'appele', called.

\subsection{Distribution of the schwa duration according to its position in word and in morpheme}

Out of our 4185 occurrences, 3445 words have an optional schwa in the word-initial syllable (e.g. 'regarde' look, 'devient' become). For these words, the distribution is similar to the one presented above. Two groups emerge with a gap in the duration distribution between 0 and $16 \mathrm{~ms}$. The mean schwa duration of the 2815 schwa-full forms is $50 \mathrm{~ms}(\sigma=$ $15)$, with close to zero skewness (0.14) and kurtosis (-0.51) coefficients. This distribution is therefore close to normality while right-skewed.

The remaining 740 words have a non-initial schwa, placed either in the second or third syllable of the word. Their distribution is similar to that of initial schwas with 2 separate sub-groups and a gap in the distribution between 0 and $17 \mathrm{~ms}$. According to what is known in the literature [e.g.[14]], these non-initial schwas have a higher frequency of elision than initial ones. Indeed, only 155 occurrences (21\%) show acoustic vocalic information. The schwa duration of these schwa-full forms (43 ms, $\sigma=17$ ) is shorter than that of initial schwas $(\mathrm{t}(2968)=5.626, \mathrm{p}<0.0001)$, the coefficients of skewness and kurtosis are respectively of 0.32 and -0.84 .

A separate analysis was also done according to the position of the schwa relative to morphological boundaries. Schwas were coded as being either morpheme-internal (3218 occurrences, e.g. 'cheval', horse) or at a morpheme boundary (938 occurrences, e.g. 'retrouver', found again), according to a rather conservative morphological analysis. Three words ('devenir', 'remarque' and 'remarquer', corresponding to 29 occurrences) for which categorisation was uncertain were excluded. The distributions of the duration of both morpheme-internal and non-internal schwas are similar to the ones presented above: schwa-less forms on one side (31\% of morpheme internal schwas; $24 \%$ of non-internal schwas) and schwa-full forms on the other side, the two subgroups being separated by a gap in the distribution between 0 and $16 \mathrm{~ms}$.

Taken together, these results show that the typical bimodal distribution of the duration of the schwas in our corpus is not dependent on the position of the schwa in the word or of the morpheme boundary. All the types of schwas analyzed are distributed over two separate subgroups: schwa-full forms with visible vocalic information and schwa-less forms defined by a lack of voicing and formant structure.

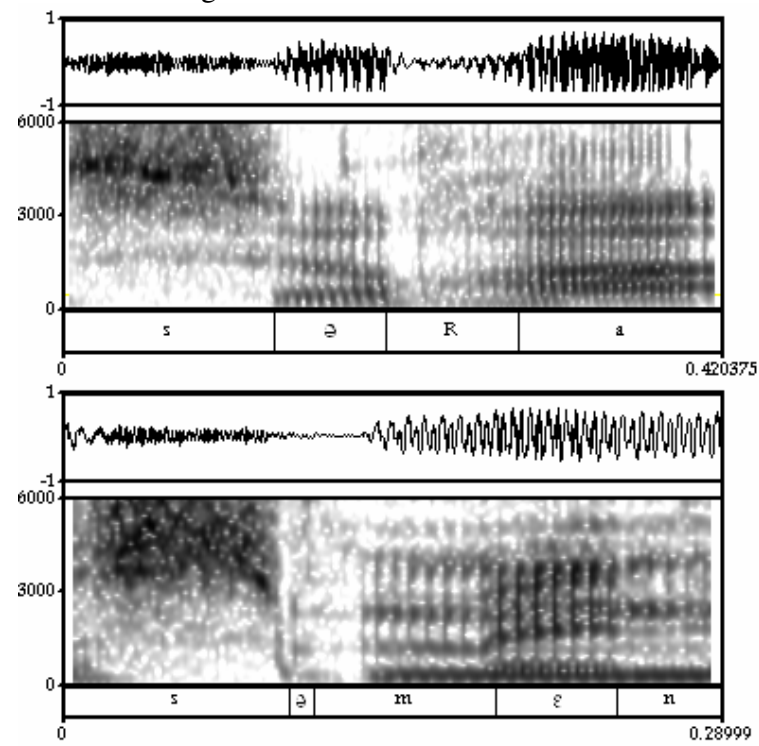

Figure 3: Schwa-full occurrences of the words 'sera' (will be) and 'semaine' (week). Note that the devoiced portion of the vowel in 'semaine' is not included in our segmentation, according to our acoustic criteria.

\section{Discussion and conclusion}

Optional schwa elision in French is defined as an alternation between the schwa-less and the schwa-full form of a word. In our corpus of radio broadcasted speech, we indeed observed that $29 \%$ of the occurrences of the words are realized with no voicing and formant structure corresponding to a schwa vowel. This process of schwa elision is considered in traditional phonological accounts as a categorical process of segmental deletion. In this study of the production of 4185 optional schwas, we have shown that there is a gap in the duration distribution of these schwas. Thus, two groups emerge with forms realized without a vocalic portion on one side, and forms realized with a vocalic portion of some duration on the other side.

Recall that according to our hypotheses, a continuous distribution, without a gap between schwa-full and schwa-less forms would have supported the view of a gradual reduction process, in which the schwa-less forms is the end-point. Our 
results, showing a bimodal distribution separated by a gap are on the contrary in support of the categorical nature of the process.

However, our results do not allow us to be assertive on this interpretation. Indeed, a categorical account is challenged by the fact that the gap we observe between the two groups is rather small. No schwas occur with a duration lesser than 16 $\mathrm{ms}$. It corresponds roughly to 2 periods for a fundamental frequency of $125 \mathrm{~Hz}$. Even though we have been very strict on our segmentation criteria, we cannot exclude a measurement error rate of 1 or 2 periods.

Along the same line, it could be argued that the gap we observe in the distribution is a by-product of the criteria we chose to define the acoustical interval corresponding to the vowel. While voicing and formant structure are the most salient cues defining a vowel (and the clearest attributes to consider when dealing with such a large corpus), we cannot ignore the fact that vowels can reduce greatly in running speech and can surface without voicing or a clear formant structure. As stated earlier devoiced vowels have not been considered here as schwa-full realizations. Nonetheless, we are reluctant to consider that modifying our segmentation criteria to include such realizations would have change the distribution to support a continuous gradual process. The spectrogram presented in figure 4 illustrates such a case. The change in intensity between the end of the [v] and the [n] could be attributed to a devoiced vowel. The portion of noise with increased energy is around $25 \mathrm{~ms}$. Hence, if this realization was categorized as schwa-full, it would not have inflated our distribution in the gap region. Similarly, if our shortest vowels, such as the one of 'semaine' in figure 3, had been segmented to include some potential devoiced or formant less portions, their duration would have been longer. This would have changed the shape of our distribution by increasing the gap between the 2 groups, but not by decreasing it.

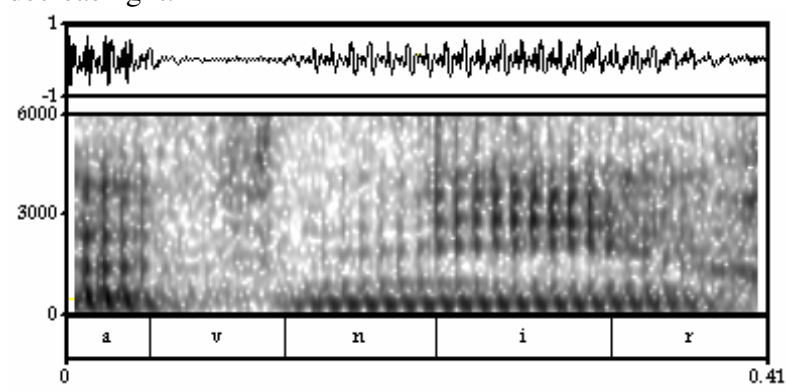

Figure 4 :Realization of the word 'avenir' (future)

An alternative explanation to consider that gives a full account of our data, is that the distribution we observed results from both a categorical and a gradual process. On the one hand, a phonological categorical process would account for the leftmost mode of the distribution. This process corresponds to the traditional optional schwa elision phenomena typical of French, in which the lexical variant produced is schwa-less. Whether this form results from a segmental deletion at one representation level or whether it corresponds to a stored lexical variant is beyond the scope of this paper. On the other hand, a gradual phonetic process of reduction would account for the gradual temporal reduction we observe within the group of the schwa-full forms. As do other segments, schwa is subject to reduction in continuous speech. We are not addressing here the question of whether this reduction is due to a mechanism of overlap, gestural reduction or target undershoot.
This dual interpretation has to be confirmed by the thorough analysis of the 1215 occurrences categorized as being schwa-less in our study. Of great interest will be the distribution of schwa-less forms and the potentially reduced schwa-full forms of specific lexical items and particular speaker productions. Further analysis is also needed to verify whether the dispersion in the realization of the schwa vowels mirrors that of other French vowels in the corpus.

The authors wish to thank G. Gravier, R. Ridouane and U. Frauenfelder for their help and suggestions.

\section{References}

[1] Côté, M.H. \& Morrison, G. "The nature of the schwa/zero alternation in French clitics: experimental and non-experimental evidence", Journal of French Language Studies, to appear.

[2] Rialland, A. "Schwa et Syllabes en Français", in L. Wetzels \& E. Sezer (Eds), Studies in Compensatory Lenghtening, Foris Publications, Dordrecht, 1986.

[3] Fougeron C. \& Steriade D. "Au Delà de la Syllabe: le Rôle des Informations Articulatoires Stockées dans le Lexique pour l'Analyse de la Chute de Schwa", JEL, Nantes, France, 122-127, 1999.

[4] Steriade, D. "Paradigm Uniformity and the PhoneticsPhonology Boundary", In M. Broe \& J. Pierrehumbert (Eds), Papers in LabPhon5, CUP, Cambridge, 1999.

[5] Browman, C. \& Goldstein, L. "Targetless" Schwa: an Articulatory Analysis", In G. Doherty \& R. Ladd (Eds), Papers in LabPhonII, CUP, Cambridge, 1992.

[6] Smorodinsky, I. "The phonology and phonetics of schwas in parisian French: an articulatory analysis", Texas Linguistic Forum, Vol. 41, 1998, p. 161-171.

[7] Barnes, J. \& Kavitskaya, D. "Phonetic analogy and schwa deletion in French", Berkeley Linguistics Society, Vol. 28, 2002, p. 39-50.

[8] Davidson, L. "Schwa elision in fast speech: segmental deletion or gestural overlap?", Phonetica, Vol. 63, 2006, p.79-112.

[9] New B., Pallier C., Ferrand L. \& Matos R. "Une base de données lexicales du français contemporain sur internet : LEXIQUE”, L'Année Psychol., Vol. 101, 2001, p. 447462. http://www.lexique.org

[10] Content, A., Mousty, P. \& Radeau, M. "Brulex, une base de données lexicales informatisée pour le français écrit et parlé”. L'Année Psychol., 90, 1990, p. 551-566.

[11] Boula de Mareüil P., Yvon F., d'Alessandro C., Auberge V., Vaissière J. \& Amelot A. "A French Phonetic Lexicon with variants for Speech and Language Processing”, $2^{\text {nd }}$ Intl Conf. on Language Resources and Evaluation (LREC), 273-276, 2000.

[12] Galliano, S., Geoffrois, E. Mostefa, D., Choukri, K., Bonastre, J.-F. \& Gravier, G. "ESTER Phase II Evaluation Campaign for the Rich Transcription of French Broadcast News", Proc. of InterSpeech 9 , Lisboa, Portugal, 2005.

[13] Boersma, P. \& Weenink D. "Praat: doing phonetics by computer" (Version 4.3.14), 2005. http://www.praat.org/

[14] Côté, M.-H., "Consonant Cluster Phonotactics: a Perceptual Approach", Ph.D Dissertation, MIT, 2000. 